\title{
Two documents
}

Cite as: CMAJ 2017 May 29;189:E750-1. doi: 10.1503/cmaj.161287

\section{CMAJ Podcasts: article reading at https://soundcloud.com/cmajpodcasts/161287-enc}

was struck by two documents in my grandfather's possession. The first, a photograph of his mother - my great-grandmother (Figure 1). The photograph is not dated but was likely taken between 1933 and 1934. The identity of her male companion is not known.

She's a young woman - beautiful, at the prime of life. Her smile is delicate and natural, the squint of her eyes visible through the tinted lenses of her round designer sunglasses. Is it a sunny day? In summer, perhaps? There is not a single cloud in the sky.

Her arms are folded neatly in front of her, her left hand gently grasping a dark overcoat that hangs elegantly over her shoulders, accentuating the crisp whiteness of her calf-length dress. Is it slightly cool? Perhaps it is autumn, after all. Variegated foliage encircles the scene.

The unknown man in the photograph is older. He is also smiling, one hand resting casually in his pocket, while the other is behind the young woman - on her waist, perhaps? The photograph of the couple suggests an intimacy, yet the young woman seems distant.

The second, a medical document (Figure 2).

"CASE History," it reads. "Admitted: October 1, 1941." Summers have passed it is now autumn.

This document contains much more and much less information. Atop the page we find the young woman's name: "FAIRHURST, Miriam nee Hull." According to the "PERSONAL History," the patient is 25 years of age and has been married for two years. She was born in Montréal.

This was not her first "attack of insanity" - according to the document, she was at the same hospital three previous times. This time, she exhibited symptoms of "sleeplessness" and "mental tension."
Diagnosis? "Manic depressive," the bracketed "(depressed)" further specifying her condition. The young woman's easy yet distant smile is here reduced to words on a page. These words - Manic depressive concrete, definitive. Certainty replaces uncertainty.

Winter passes. Spring, then summer. Autumn, and then winter again. Although the photograph captures a moment, fleeting and ephemeral, this medical document subsumes over one year. Sixteen months. Four hundred and 97 days. "Patient discharged recovered on February 8, 1943."

To where did she return? To her parents? Her mother had died, an inpatient at the same hospital. Her father is listed as the primary correspondent, his address located in the working-class neighbourhood of Pointe-Saint-Charles. Why not to her husband? His identity is not listed anywhere, a conspicuous absence.

In the photograph, the young woman stands together, yet apart, from her male companion, her smile independent and defiant. In the CASE HISTORY, she is defined in relation to male figures - her husband, father, physician and reverend - from her occupation of "housewife" to her "MEANS of SUBSISTENCE." Of her gender and sexuality, we learn that she has "No filthy habits."

Attention is drawn to the heading "CHILDREN," highlighted in the text: " 1 boy age 6 residing at 1163 Essex Ave. Apt. A." Did this boy know where his mother had gone?

My grandfather knew very little about his mother's life. We do know that Miriam Hull was born in Montréal on Dec. 18, 1916. It is likely that she was first admitted to the Verdun Protestant Hospital, an asylum on the Southwest Island of Montréal, in 1935 after giving birth to her first and only child, Ross Edward Hull. He was born on Jan. 24, 1935, at a "Home for Unwed Mothers." We do not know the identity of

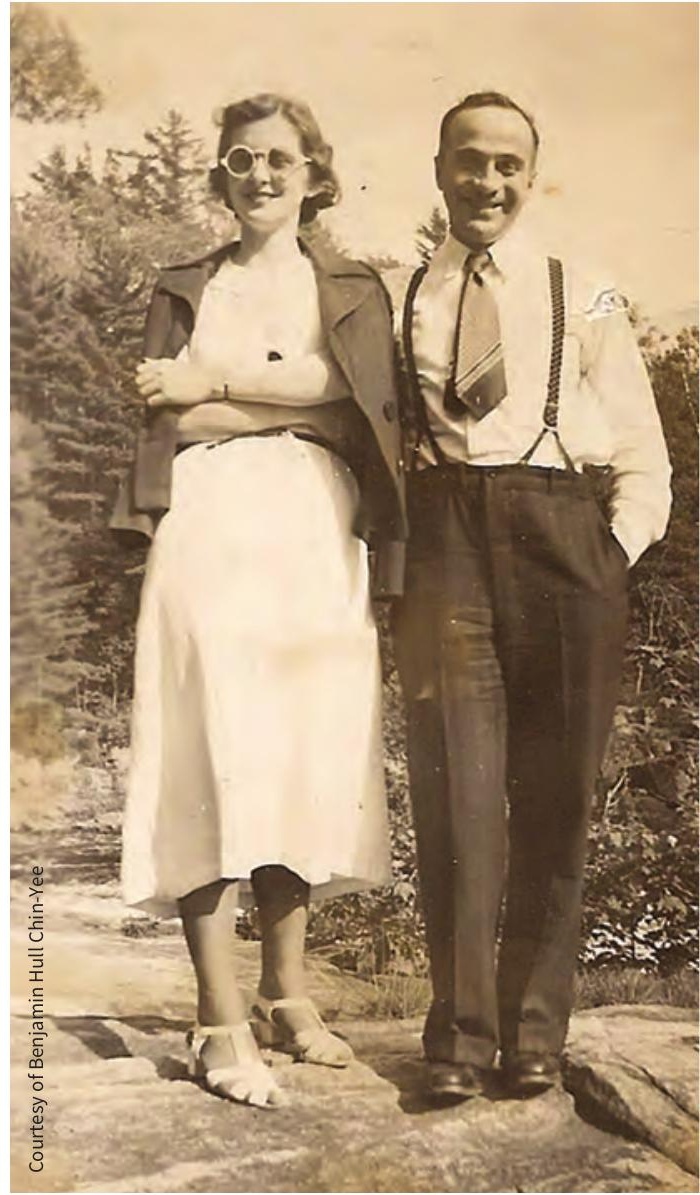

Figure 1: My great-grandmother and an unknown acquaintance, circa 1933.

the father. In 1939, she married and took the name "FAIRHURST." Mr. FAIRHURST left to go to war and never returned. He was presumed dead. We later discovered that he had survived the war but had never made contact with Miriam or his stepson.

Miriam's illness was severe and unstable, and she was not able to care consistently for her son, who was in and out of foster care from the time of his birth. Growing up, I remember my grandfather would only rarely describe his turbulent childhood, his relative silence betraying 
the stigma, shame and abandonment that he had experienced as a result of his mother's condition. Later in his life, he would occasionally visit his mother in hospital but avoided bringing his own children, as if to spare them the distress that he associated with the institution. As he experienced his own struggles with depression, he maintained this fear and distrust of medical institutions, which he continued to view as a "place of no return."

Miriam never recovered sufficiently to live and function independently for any substantial period of time. She was in hospital for most of her life and died on July 9, 1985, at the Porteous Pavilion of the Douglas Hospital, where she had been an inpatient for many years.

In the years before Miriam's death, unbeknownst to my grandfather, my mother had visited her in hospital. She witnessed her highs and her lows but also her kind, strong personhood that shone through the peaks and troughs of her illness. Unlike my grandfather, my mother remembered the hospital as a sad but caring place, and these experiences eventually led her to pursue a career as a physician working in mental health.

My great-grandmother lived through many autumns. Through many summers and winters. A World War came and went. She lost a husband. Psychiatry found new drugs, new diagnoses. Institutions changed names, staff turned over. Her son was married, my mother was born. The photograph and CASE HISTORY offer two divergent narratives - two representations of my greatgrandmother's life.

As physicians, we strive to "know our patients." This well-intentioned task must be approached with humility. Diagnoses give us a sense of certainty. They facilitate communication, they indicate treatment. But they do not capture the dense and diffuse webs of meaning surrounding each individual life. "Knowing your patient" entails entering a lifeworld - it entails spinning and unspinning webs of meaning, recognizing their extension across space and time.

As a medical student, I am aware of the role of physicians in constructing narratives. As a son and grandson, I have witnessed the impact that these narratives can have across generations. In the CASE HISTORY, I am confronted with direct, concrete, but also value-

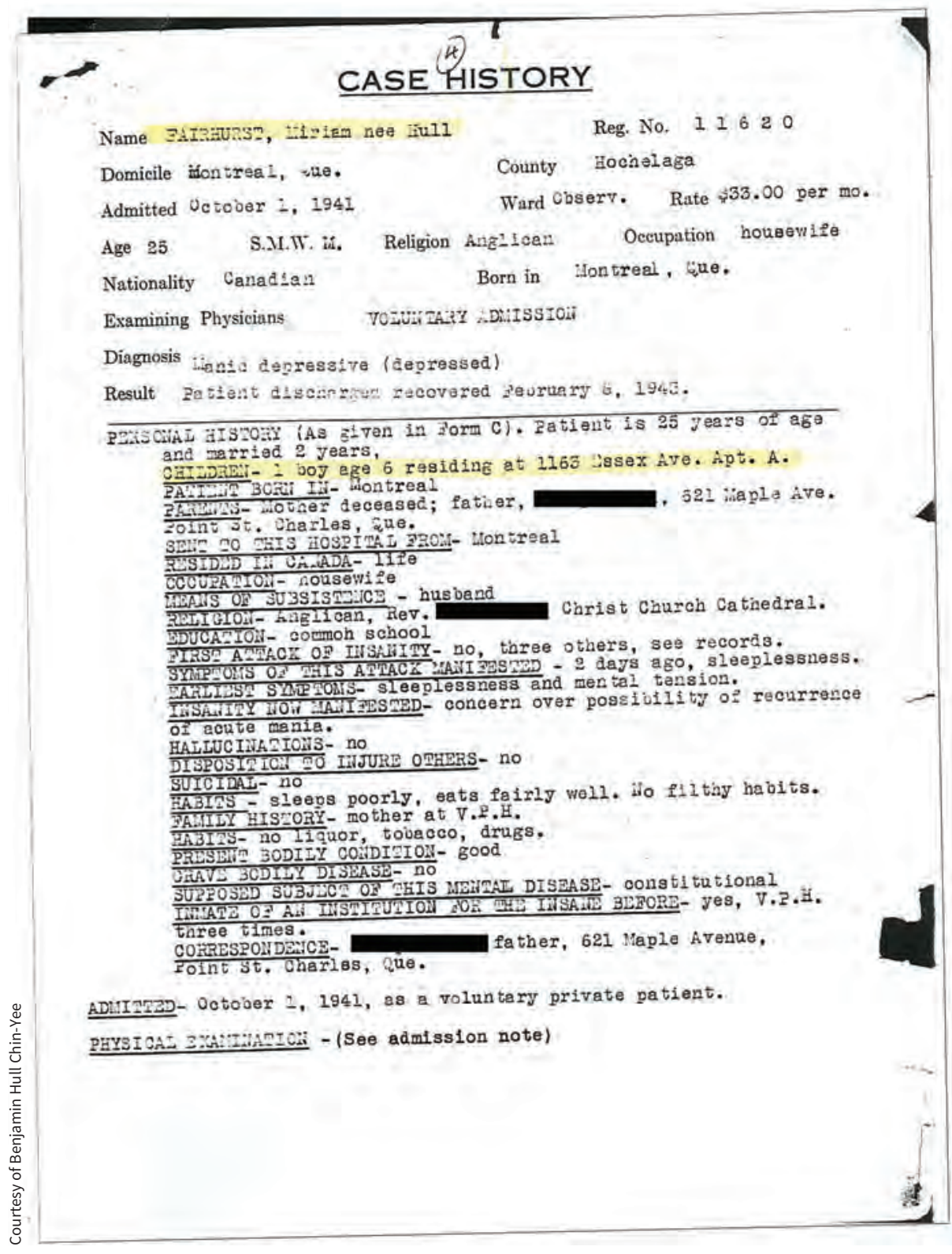

Figure 2: Case History for my great-grandmother from 1943.

laden, judgmental language. I am led to wonder about the narratives we construct every day in clinical practice - what is captured, what is lost, and how might these look to observers from a later period?

My great-grandmother had a diagnosis of "manic depression." She also had a son, a granddaughter and, now, a greatgrandson. As I learn about my greatgrandmother, piece by piece, photograph by photograph, document by document, I begin to reconstruct her life, spinning the webs of meaning of which I am inescapably a part.

\section{Benjamin Hull Chin-Yee BSc MA}

Class of 2017, Faculty of Medicine, University of Toronto, Toronto, Ont.

This article has been peer reviewed.

This is a true story. The owners of these documents have given their consent for this story to be told.

Acknowledgments: The author would like to thank Allan Peterkin and Pablo Diaz for helpful comments on previous versions of this piece. He would especially like to thank his greatgrandmother, Miriam Maud Hull, whom he never met but whose story lives on through his grandparents, Charlotte Legault-Hull and Ross Edward Hull, and his mother, Marie Louise Hull. 